\title{
N250 latency and decision time
}

\author{
JAMES TOWEY, FRED RIST, GAD HAKEREM, \\ DANIEL S. RUCHKIN, and SAMUEL SUTTON \\ Department of Psychophysiology, New York State Psychiatric Institute, New York, New York 10032
}

\begin{abstract}
Eight subjects counted the rarer of two clicks under two levels of difficulty of discrimination. Event-related potentials showed a significant lengthening of N250 and P300 latency when the discrimination was more difficult. These findings confirm those of Ritter et al. (1979) despite the following procedural differences: (1) Stimuli differed in intensity rather than pitch, (2) the task involved silent counting rather than reaction time, and (3) statistical analyses were computed across subjects rather than within subjects. We conclude that the N250 latency shift reflects an increase in decision time as a consequence of greater difficulty. The current findings also support the Ritter et al. (1979) conclusion that the P300 latency increase is secondary to the N250 increase. Although P300 amplitude decreased with increased task difficulty, as predicted by the equivocation formulation of Ruchkin and Sutton (1979), this trend failed to reach the required .01 level of statistical significance.
\end{abstract}

Ritter, Simson, Vaughan, and Friedman (1979) suggested that at least one of the cognitive roles formerly assumed to be mediated by the P300 component of the human event-related potential, namely, its relationship to difficulty of sensory discrimination, is more probably mediated by the $\mathrm{N} 250$ component $\left(\mathrm{N}_{2}\right.$ in Ritter et al.). They found intrasubject correlations between the latency of $\mathrm{N} 250$ and reaction time for both easy and difficult discrimination conditions. For three out of four subjects, mean N250 latency was longer for the difficult discrimination. They concluded that N250 is involved in the "decision process related to sensory discrimination" (Ritter et al., 1979, p. 1,360).

The present study, which was undertaken without knowledge of the Ritter et al. (1979) findings, obtained results that support their conclusions. Our sensory task involved the intensity dimension rather than the pitch dimension used by Ritter et al. Futhermore, we used silent counting rather than reaction time. Positive findings would therefore strengthen the generality of the formulation. In addition, eight subjects were run, so that statistical analysis could be performed across subjects rather than within subjects.

The current study provided a partial replication of the Johnson and Donchin (1978) finding that P300 amplitude was not altered in the counting task as a function of intensity differences between stimuli. Their negative finding is inconsistent with other findings that show P300

This research was supported in part by a grant (to Fred Rist) from the German Federal Republic. We wish to thank Patricia Tueting, Walter Ritter, and Muriel Hammer for a critical reading of the manuscript, Patricia Cohen for advice on statistical analysis, Robert Laupheimer and Ben Djoleto for assistance with instrumentation, and Vilma Maschio for typing the manuscript. Fred Rist is now at the Department of Psychology, University of Konstanz, West Germany. Daniel S. Ruchkin is at the Department of Physiology, University of Maryland School of Medicine. becomes smaller as the "immediacy and ease with which a decision can be made" decreases. This is the equivocation concept developed by Ruchkin and Sutton $(1979$, p. 177).

\section{METHOD}

Eight students served as subjects (two females, six males). The median age was 23 years (range: 17-27). Subjects were paid an hourly rate plus a bonus for accuracy of count.

A Beckman miniature biopotential skin electrode was fixed at vertex and referred to linked ears. A neck electrode served as ground. The EEG was amplified at a gain of 10,000 by a Princeton Applied Research amplifier (TM 113). Bandpass was from .03 to $30 \mathrm{~Hz}$. The recording epoch was from $100 \mathrm{msec}$ prior to the click to $1,180 \mathrm{msec}$ after the click. A Fabri-Tek 1052 signal averager was used on-line with a sampling rate of $200 \mathrm{~Hz}$. Sixty-four sweeps were used for each average, which was plotted on a Hewlett-Packard plotter (7030 AM).

Subjects sat in a sound-treated room. Clicks of $.2 \mathrm{msec}$ duration were presented through an overhead loudspeaker. Subjects silently counted the less frequent of two clicks $(p=.33)$ and reported the total after each block of trials. Order of clicks was random, except for the restriction that no more than three rare clicks occurred in sequence. Interstimulus intervals were fixed at $1,600 \mathrm{msec}$. Each block consisted of 80 clicks, with 5 nontarget clicks occurring at the beginning to provide the reference intensity. In half of the blocks, the difference between targets and nontargets was $10 \mathrm{~dB}$ (easy discrimination); in the other half, the difference was $5 \mathrm{~dB}$ (difficult discrimination).

Event-related potentials evoked by target clicks were averaged during both easy and difficult tasks. Because we were unable to obtain average event-related potentials to target and nontarget clicks from the same blocks, the same clicks were presented as targets and nontargets in different blocks. ${ }^{1}$ (For example, when the soft click was the target, subjects counted soft rare clicks while target potentials were recorded and counted loud rare clicks while nontarget potentials were recorded.) For four subjects, the softer clicks served as target; for the other four subjects, the louder clicks so served. Each subject repeated the task at a second level of click intensities in order to establish that task difficulty effects were not limited to a given intensity level.

Table 1 shows the eight combinations of click pairs used. They were specified in terms of the median sensation level 
Table 1

Sensation Level of Stimuli

\begin{tabular}{llccccc}
\hline & & \multicolumn{3}{c}{ Discrimination } \\
\cline { 3 - 4 } \cline { 3 - 6 } \cline { 5 - 7 } & & \multicolumn{3}{c}{ Easy } & & \multicolumn{2}{c}{ Difficult } \\
\cline { 3 - 4 } \cline { 5 - 7 } Low Intensity & NT & & T & NT \\
\hline \multirow{3}{*}{ High Intensity } & Count Soft & 20 & 30 & & 20 & 25 \\
& Count Loud & 30 & 20 & & 30 & 25 \\
& Count Soft & 25 & 35 & & 25 & 30 \\
& Count Loud & 35 & 25 & & 35 & 30 \\
\hline
\end{tabular}

Note $-T=$ target,$N T=$ nontarget .

obtained by finding thresholds for three subjects $(54,57$, and $58 \mathrm{~dB}$ below an arbitrary constant level).

Subjects were told to keep their eyes closed ${ }^{1}$ during the counting task. Accuracy of count was stressed. Subjects earned an additional 25 cents for a correct count of targets in each block of 80 trials.

Two scorers (J.T. and F.R.) who were blind with respect to experimental conditions made independent measurements of amplitude and latency. Instances of disagreement were resolved by a third, independent rater (S.S.). Components were taken as the largest peaks in the latency ranges 40$100 \mathrm{msec}$ (P60), 60-135 msec (N100), 105-225 msec (P200), $140-300 \mathrm{msec}(\mathrm{N} 250)$, and $250-550 \mathrm{msec}$ (P300). The average voltage during the $50-\mathrm{msec}$ epoch prior to the eliciting stimulus served as the baseline.

Components for nontarget clicks were not included in the data analysis because alpha often contaminated late components. Alpha contamination was less of a problem for target stimuli, presumably due to alpha blocking associated with counted rare events.

\section{RESULTS}

Average event-related potentials for one subject are shown in Figure 1 for target clicks plotted separately for easy and difficult conditions, as well as for high and low intensity levels. Notice that the latency of N250 is longer during the difficult, as opposed to the easy, discrimination task.

All latency and amplitude data associated with target clicks were evaluated for each component separately using a two-way analysis of variance (BMDP 2V). Factors were task difficulty (5- vs. 10-dB difference between target and nontarget) and stimulus intensity of click pairs (high vs. low), with repeated measures for both factors. The effect of instructions (count loud vs. count soft target) was balanced experimentally but was not evaluated because there were only four subjects in each of the two conditions. Due to the large number of statistical tests, the .01 confidence level was adopted. Only N250 and P300 findings met this criterion.

Table 2 shows latencies (left panel) and amplitudes (right panel) of individual subjects for N250 and P300 components evoked by target clicks during easy and difficult discrimination tasks for both intensity levels of target stimuli. P200 data were included in Table 2 because they help clarify N250 and P300 effects as detailed in the Discussion section. Data of soft targets appear in the top four rows of each intensity condition; data from loud targets appear in the bottom four rows of each intensity condition. The bottom three rows of the table show these data averaged across subjects for each experimental condition.

Latency changed significantly from easy to difficult discrimination tasks for $\mathrm{N} 250[\mathrm{~F}(1,7)=22.87$, $\mathrm{p}=.002]$ and for $\mathrm{P} 300[\mathrm{~F}(1,7)=13.53, \mathrm{p}=.008]$. The direction of these latency effects can be seen by inspecting the means shown in the bottom row of Table 2. As a result of increasing task difficulty, mean latency of 250 increased from 208 to $238 \mathrm{msec}$, and that of P300 increased from 331 to $350 \mathrm{msec}$. These group trends were found consistently among individual subjects for both $\mathrm{N} 250$ and P300.

None of the comparisions of easy vs. difficult for the amplitude measures reached statistical significance at the .01 level of confidence. For both latency and amplitude measures, neither intensity nor its interaction with the task difficulty reached statistical significance.

\section{DISCUSSION}

Increasing the difficulty of an auditory discrimination task that involves counting the rarer of two events results in an increase in N250 latency. This finding is consistent with the formulation of Ritter et al. (1979) that N250 is involved in the "decision process related to sensory discrimination." Using intrasubject difference tests, they found significantly longer

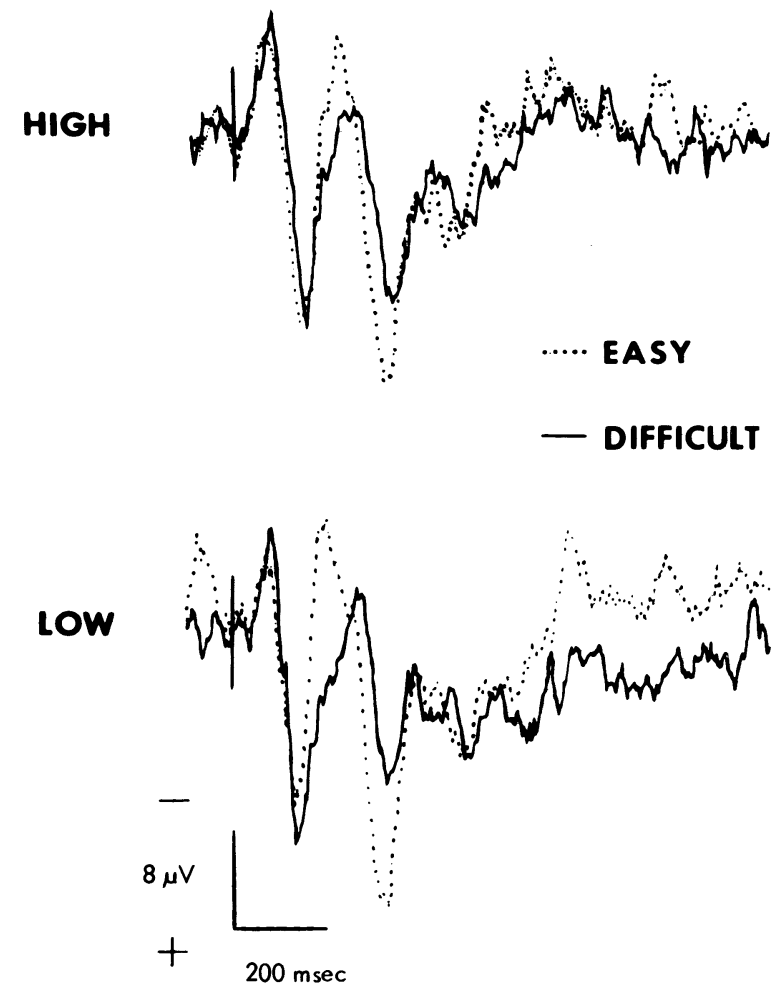

Figure 1. Average evoked potentials associated with target clicks for one subject during easy (dotted lines) and difficult (solid lines) conditions for both high (upper panels) and low (lower panels) intensities. Traces began 100 msec before click onset (vertical bar) and ended 1,180 msec later. 
Table 2

\begin{tabular}{|c|c|c|c|c|c|c|c|c|c|c|c|c|c|}
\hline \multirow[b]{3}{*}{$\mathrm{T}$} & \multirow[b]{3}{*}{$\mathrm{S}$} & \multicolumn{6}{|c|}{ Latency } & \multicolumn{6}{|c|}{ Amplitude } \\
\hline & & \multicolumn{3}{|c|}{ Easy Discrimination } & \multicolumn{3}{|c|}{ Difficult Discrimination } & \multicolumn{3}{|c|}{ Easy Discrimination } & \multicolumn{3}{|c|}{ Difficult Discrimination } \\
\hline & & P200 & $\mathrm{N} 250$ & P300 & P200 & $\mathrm{N} 250$ & P300 & $\mathbf{P} 200$ & $\mathrm{~N} 250$ & P300 & $\mathbf{P} 200$ & $\mathrm{~N} 250$ & P300 \\
\hline & & \multicolumn{12}{|c|}{ Low Intensity } \\
\hline Soft & $\begin{array}{l}1 \\
2 \\
3 \\
4\end{array}$ & $\begin{array}{l}175 \\
140 \\
145 \\
160\end{array}$ & $\begin{array}{l}230 \\
190 \\
213 \\
270\end{array}$ & $\begin{array}{l}385 \\
340 \\
338 \\
450\end{array}$ & $\begin{array}{l}180 \\
160 \\
155 \\
158\end{array}$ & $\begin{array}{l}245 \\
223 \\
280 \\
283\end{array}$ & $\begin{array}{l}360 \\
353 \\
345 \\
488\end{array}$ & $\begin{array}{r}9.0 \\
.2 \\
7.0 \\
13.4\end{array}$ & $\begin{array}{r}-4.0 \\
10.0 \\
4.1 \\
.4\end{array}$ & $\begin{array}{l}17.8 \\
15.6 \\
12.0 \\
12.4\end{array}$ & $\begin{array}{r}5.6 \\
.6 \\
9.4 \\
13.6\end{array}$ & $\begin{array}{r}-2.1 \\
4.6 \\
1.7 \\
4.8\end{array}$ & $\begin{array}{r}10.5 \\
10.2 \\
6.8 \\
10.0\end{array}$ \\
\hline Loud & $\begin{array}{l}5 \\
6 \\
7 \\
8\end{array}$ & $\begin{array}{l}125 \\
148 \\
148 \\
180\end{array}$ & $\begin{array}{l}150 \\
213 \\
208 \\
190\end{array}$ & $\begin{array}{l}285 \\
295 \\
328 \\
273\end{array}$ & $\begin{array}{l}145 \\
155 \\
145 \\
165\end{array}$ & $\begin{array}{l}188 \\
233 \\
215 \\
215\end{array}$ & $\begin{array}{l}300 \\
305 \\
353 \\
313\end{array}$ & $\begin{array}{r}3.3 \\
20.0 \\
15.2 \\
5.6\end{array}$ & $\begin{array}{l}-1.2 \\
-6.6 \\
-2.8 \\
-4.6\end{array}$ & $\begin{array}{l}23.4 \\
17.8 \\
17.2 \\
12.0\end{array}$ & $\begin{array}{r}5.0 \\
15.0 \\
12.4 \\
6.4\end{array}$ & $\begin{array}{r}-2.4 \\
1.6 \\
-.4 \\
-1.6\end{array}$ & $\begin{array}{l}21.6 \\
14.5 \\
14.5 \\
10.4\end{array}$ \\
\hline Soft & $\begin{array}{l}1 \\
2 \\
3 \\
4\end{array}$ & $\begin{array}{l}163 \\
158 \\
145 \\
163\end{array}$ & $\begin{array}{l}240 \\
210 \\
238 \\
223\end{array}$ & $\begin{array}{l}371 \\
350 \\
330 \\
340\end{array}$ & $\begin{array}{l}188 \\
155 \\
105 \\
160\end{array}$ & $\begin{array}{l}260 \\
225 \\
260 \\
265\end{array}$ & $\begin{array}{l}\text { High } \\
398 \\
355 \\
345 \\
380\end{array}$ & $\begin{array}{c}\text { ntensity } \\
10.6 \\
-1.2 \\
8.8 \\
12.8\end{array}$ & $\begin{array}{r}-5.7 \\
8.3 \\
3.9 \\
3.0\end{array}$ & $\begin{array}{r}18.6 \\
6.0 \\
11.7 \\
12.4\end{array}$ & $\begin{array}{r}4.8 \\
-\quad .9 \\
9.0 \\
13.1\end{array}$ & $\begin{array}{r}-1.2 \\
8.6 \\
.7 \\
-1.0\end{array}$ & $\begin{array}{r}9.2 \\
9.0 \\
8.1 \\
12.6\end{array}$ \\
\hline Loud & $\begin{array}{l}5 \\
6 \\
7 \\
8\end{array}$ & $\begin{array}{l}133 \\
168 \\
145 \\
150\end{array}$ & $\begin{array}{l}140 \\
233 \\
200 \\
178\end{array}$ & $\begin{array}{l}280 \\
303 \\
320 \\
310\end{array}$ & $\begin{array}{l}175 \\
178 \\
140 \\
220\end{array}$ & $\begin{array}{l}210 \\
238 \\
210 \\
255\end{array}$ & $\begin{array}{l}300 \\
320 \\
330 \\
355\end{array}$ & $\begin{array}{r}1.6 \\
11.8 \\
7.6 \\
4.4\end{array}$ & $\begin{array}{l}-.9 \\
-4.6 \\
-1.6 \\
-2.2\end{array}$ & $\begin{array}{l}18.1 \\
15.8 \\
10.2 \\
12.4\end{array}$ & $\begin{array}{r}10.6 \\
12.0 \\
11.4 \\
6.6\end{array}$ & $\begin{array}{r}-8.8 \\
.5 \\
-3.1 \\
-1.5\end{array}$ & $\begin{array}{l}13.6 \\
14.6 \\
13.0 \\
10.6\end{array}$ \\
\hline \multicolumn{14}{|c|}{ Average Across Subjects } \\
\hline $\begin{array}{l}\text { L Inte } \\
\text { H Inte } \\
\text { Mean }\end{array}$ & $\begin{array}{l}\text { ensity } \\
\text { ensity }\end{array}$ & $\begin{array}{l}153 \\
153 \\
153\end{array}$ & $\begin{array}{l}208 \\
208 \\
208\end{array}$ & $\begin{array}{l}337 \\
326 \\
331\end{array}$ & $\begin{array}{l}158 \\
165 \\
162\end{array}$ & $\begin{array}{l}235 \\
240 \\
238\end{array}$ & $\begin{array}{l}352 \\
348 \\
350\end{array}$ & $\begin{array}{l}9.2 \\
7.1 \\
8.1\end{array}$ & $\begin{array}{r}-.6 \\
.0 \\
-.3\end{array}$ & $\begin{array}{l}16.0 \\
13.2 \\
14.6\end{array}$ & $\begin{array}{l}8.5 \\
8.3 \\
8.4\end{array}$ & $\begin{array}{r}.8 \\
-\quad .7 \\
.0\end{array}$ & $\begin{array}{l}12.3 \\
11.3 \\
11.8\end{array}$ \\
\hline
\end{tabular}

Note-Minus signs for amplitude measures indicate that the component is not in the expected direction in relation to the baseline. $T=$ target,$S=$ subject,$L=$ low,$H=$ high.

latencies for $\mathrm{N} 250$ for the difficult than for the easy discrimination condition in three out of their four subjects. The finding relating $\mathrm{N} 250$ to discrimination is further strengthened by the fact that it has now been demonstrated to operate when task difficulty was manipulated along the intensity continuum as well as along the pitch continuum. Equally important is the fact that we obtained latency differences for N250 even in a non-reaction time task.

All subjects reported greater difficulty in the counting task with the smaller intensity differences between targets and nontargets. The low-intensity arrangement produced counting performances of $98 \%$ for easy and $92 \%$ for difficult tasks; the high-intensity arrangement produced a counting performance of $99 \%$ for both easy and difficult tasks. Because accuracy differences were small (low intensity) or nonexistent (high intensity), it seems that only a moderate increase in task difficulty was sufficient to cause the above latency shifts of $\mathrm{N} 250$ and $\mathrm{P} 300$.

Some insight into the longer N250 latency for the more difficult task found both by us and by Ritter et al. (1979) may be obtained by comparing these findings with those of Hammond, Silva, Klein, and Teas (1979). In their experimental paradigm, the decision of the subjects was delayed by the manipulation of the duration of the stimuli. [This is reminiscent of techniques used in the past by Sutton, Tueting, Zubin, and John (1967) to manipulate the latency of P300.] Hammond et al. found that N250 (and also P300) occurred at a fixed latency following the offset of the stimulus. This was the earliest point in time at which the subjects could make the experimentally required decision. What seems to be shared by these paradigms is the dependence of N250 latency on decision time. In the current study and in Ritter et al., the experimental increase in the difficulty of discrimination apparently increases decision time, which is reflected by an increase in N250 latency.
Ritter et al. (1979) and we also obtained a longer P300 latency for the more difficult task (also, see Hammond et al., 1979; Kutas, McCarthy, \& Donchin, 1977). However, Ritter et al. justifiably emphasized the N250 findings, since N250 is the earlier component. N250 was found to occur consistently earlier than the initiation of the motor response, while P300 was often found to occur after the initiation of the motor response.

The present study sheds more light on this issue. The earlier P200 does not shift significantly with increased task difficulty $(F=2.40)$. The difference in latency between P200 and N250 as a function of task difficulty does reach statistical significance $[F(1,7)=11.03, p=.01]$, showing larger differences when the task is more difficult; the difference between N250 and $P 300$ is not statistically significant $(F=3.03)$. This pattern of findings suggests that P200 does not increase in latency, N250 does, and P300 increases in latency as a result of the N250 latency increase. The last inference is supported by the fact that the difference in latencies between easy and difficult for N250 and P300 are of the same order of magnitude $(30 \mathrm{msec}$ for $\mathrm{N} 250,19 \mathrm{msec}$ for $\mathrm{P} 300$ ). The $11-\mathrm{msec}$ difference in the effect of difficulty for N250 and P300 may reflect the different latency variability of the two components. Finally, P300 latency was correlated with $\mathrm{N} 250$ latency both for the easy condition $(r=.78)$ and for the difficult condition $(r=.72)$.

The involvement of the $\mathrm{N} 250$ region in sensory discrimination processes has also been shown by Tueting (1979). In her study, subjects made a decision of whether an interval between two clicks was shorter or longer than a standard. The issue of relative ease or difficulty did not arise since, unknown to the subjects, the test interval was always identical to the standard. She found that in the response to the click marking the end of the interval, the $\mathrm{N} 250$ region was more negative when intervals were judged longer than the standard than when intervals were judged shorter than the standard. 


\section{TOWEY, RIST, HAKEREM, RUCHKIN, AND SUTTON}

The decrease of amplitude of P300 with increased difficulty, as predicted by the equivocation formulation of Ruchkin and Sutton (1979) did not reach statistical significance at the .01 confidence level. Thus our findings do not contradict the negative findings of Johnson and Donchin (1978) for the counting task. However, it should be noted that for the low-intensity arrangement all subjects showed smaller P300 amplitudes for the difficult condition. The main effect of task difficulty in the analysis of variance also showed a clear trend $[F(1,7)=8.80$, $p=.02]$. Thus the present findings suggest that the effect of equivocation tends to be variable in the counting task and that some alteration in the experimental design or a new study with a larger number of subjects might result in a statistically significant finding.

An estimate of the contribution of the eyes-closed procedure was obtained by replicating at the low-intensity level for one subject in another laboratory that permitted the editing of artifacts due to eye movements (deflections greater than 40 microV). The counting task was performed during alternate blocks of eyes closed and eyes open (when a small light was fixated). Just as seen in Figure 1, target data showed a clear increase in N250 latency for the more difficult discrimination. This relationship held whether eyes were open or closed, but effects appeared stronger with eyes open. For nontarget clicks, alpha was found to be more marked in the eyes-closed condition. The proportion of trials rejected for eye artifact (about 1/6) was the same in the eyes-closed and the eyes-open conditions.

Equivalent levels of eye artifact during these two conditions suggest that the decrease in eye blinks when eyes were closed rather than open was compensated for by an increase in other kinds of eye movement. Since the report by Waszak and Obrist (1969) of serious artifacts due to eye movements when eyes were closed, this procedure has been avoided despite potential usefulness for working with populations who have difficulty in avoiding blinking (e.g., children and psychiatric patients). Although evoked potentials were smaller with eyes closed than with eyes open, our pilot data indicated the same trend with respect to the effect of task difficulty between the two conditions. Hence, our closed-yes arrangement provided a weak substitute for a procedure of editing EOG artifacts, but it provided a strong demonstration of the generalizability of the Ritter et al. (1979) latency effect across different procedural conditions.

\section{REFERENCES}

Hammond, E. J., Silva, D. A., Klein, A. J., \& Teas, D. C. A technique for separating endogenous from exogenous human cortical potentials. Electroencephalography and Clinical Neurophysiology, 1979, 46, 482-485.

Johnson, R., \& Donchin, E. On how P300 amplitude varies with the utility of the eliciting stimuli. Electroencephalography and Clinical Neurophysiology, 1978, 44, 424-437.

Kutas, M., McCarthy, G., \& Donchin, E. Augmenting mental chronometry: The P300 as a measure of stimulus evaluation time. Science, 1977, 197, 792-795.

Ritter, W., Simson, R., Vaughan, H., \& Friedman, D. A brain event related to the making of a sensory discrimination. Science, 1979, 198, 1358-1361.

Ruchis, D. S., \& Sutton, S. Equivocation and P $\overline{300}$ amplitude. In D. Otto (Ed.), Multidisciplinary perspectives in eventrelated brain potential research. Washington, D.C: U.S. Government Printing Office, 1979.

Sutton, S., Tueting, P., Zubin, J., \& John, E. R. Information delivery and the sensory evoked potential. Science, 1967, 155, 1436-1439.

Tueting, P. Average evoked potentials and time perception. In D. Otto (Ed.), Multidisciplinary perspectives in event-related brain potential research. Washington, D.C: U.S. Government Printing Office, 1979.

WaszaK, M., \& Obrist, W. Relationship of slow potential changes to response speed and motivation in man. Electroencephalography and Clinical Neurophysiology, 1969, 27, 113-120.

\section{NOTE}

1. A move of the laboratory to new quarters had rendered some of the equipment inoperative, which prevented both the recording of data onto magnetic tape for off-line analysis and the editing of eye movement trials. Given these limitations, subjects were instructed to close their eyes while counting (see Discussion), and evoked responses were recorded in alternate and counterbalanced blocks for target clicks (three to four blocks) and for nontarget clicks (two blocks) for each experimental condition.

(Received for publication February 18, 1980.) 